\title{
No-deal Brexit imperils Christmas deliveries
}

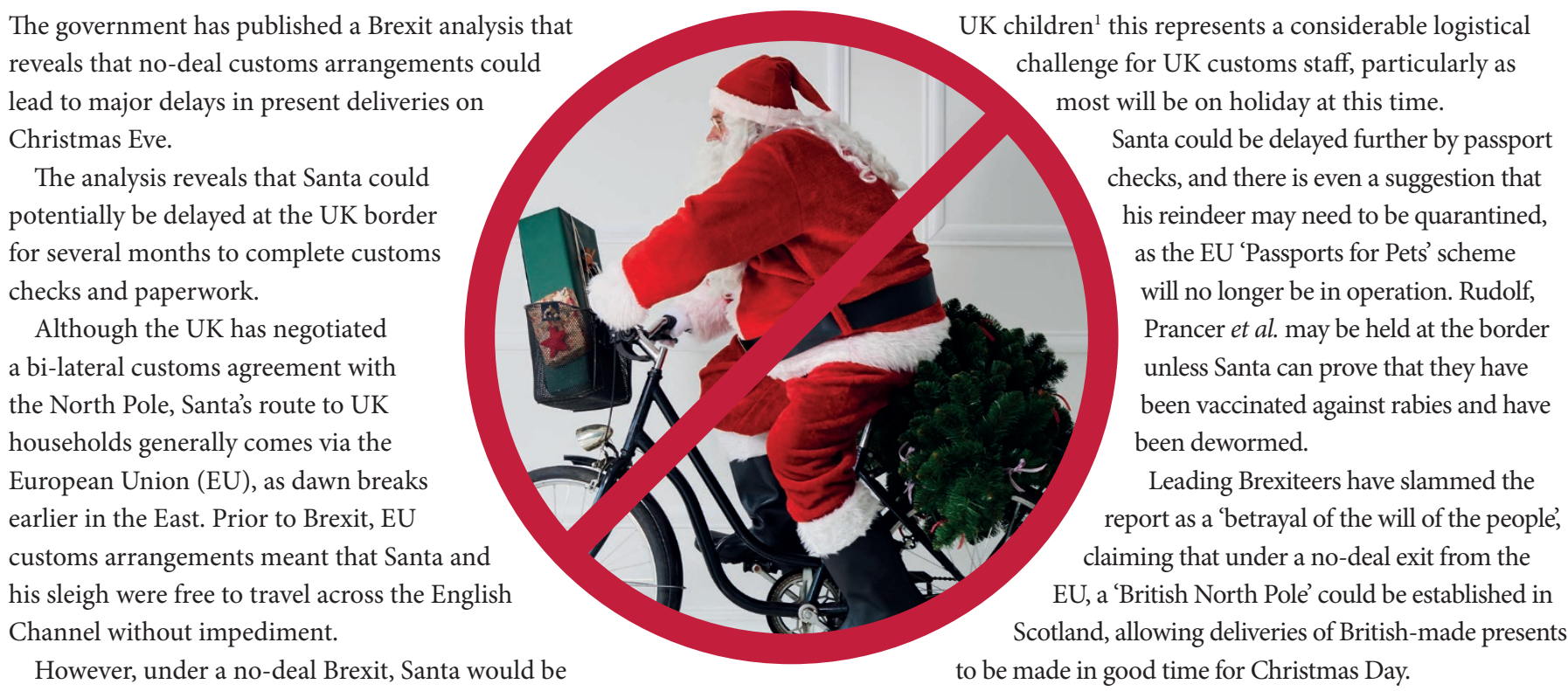

forced to wait at the UK border for his cargo to be inspected. Since

he is estimated to deliver approximately 9.44 million presents to

1. National Air Traffic Services. Route planning for Santa this Christmas Eve. NATS, 2013.

\section{Employment status of tooth fairies in doubt}

The self-employed status of tooth fairies has been called into doubt following recent rulings in employment tribunals against Uber and Pimlico Plumbers.

The British Tooth Fairy Association (BTFA) has recently contacted its members to warn them that HMRC is contacting individual tooth fairies to examine their contracts.

Tooth fairies are currently considered to be self-employed and as such, are liable for Class 2/4 National Insurance, not Class 1.

However, following renewed interest in the so-called 'gig economy' two cases at the Court of Appeal have now ruled that, despite the fact that an individual's contract defines them as self-employed, they are in fact 'workers', meaning that they are entitled to the national living wage, statutory sick pay and other benefits.

Previously, the fact that tooth fairies were not obliged to work fixed hours, could set their own rates, use their own equipment, and were able to send a substitute tooth fairy if they wished, were all considered to confer self-employed status.

This comes on the back of news that tooth fairy payments dropped in 2017 by
$11 \%$ (the second year of falling values) with average pay-outs in the UK dropping to

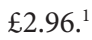

A BTFA spokesperson commented: 'Falling tooth values reflect the worsening financial situation of tooth fairies in the UK. Our members simply can't afford to pay the going rate any longer.'

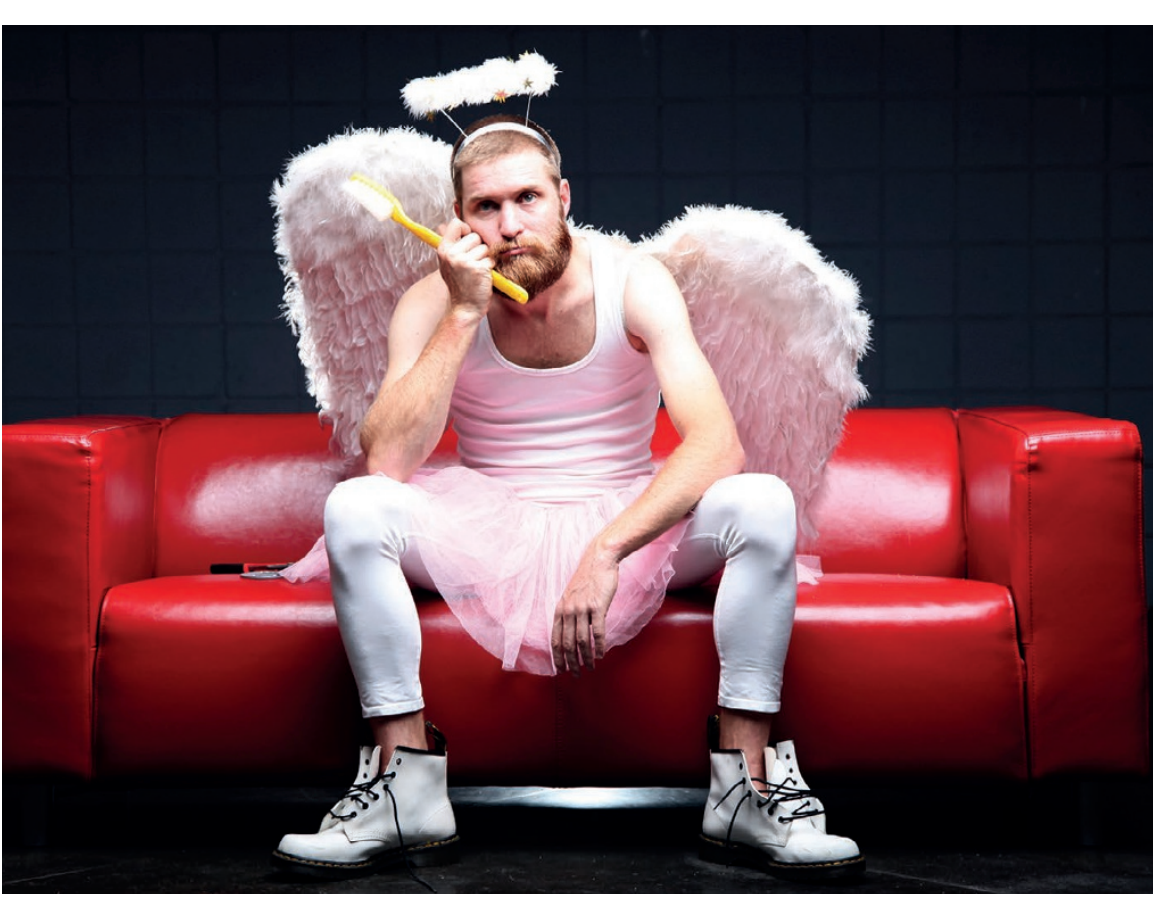

The BTFA has previously reported a recruitment crisis amongst tooth fairies, with $58 \%$ of dental imps planning on leaving the profession, and a shortage of fairies meaning that some children's teeth are not collected.

\section{The Original Tooth Fairy Poll. The Tooth Fairy Index. Available at http://theoriginaltoothfairypoll.com (accessed December 2018).}

